\title{
Do "Incidental Melanomas" Exist? If so, how many are they? High Time to Decide
}

\author{
Giovanni Luigi Capella*
}

Dermatology \& STD, Milan, Italy

\begin{abstract}
Do "Clinically Insignificant, HIstological MElanoma-Like Lesions" (CIHIMELL) - to wit, merely incidental, looking-like-melanoma lesions devoid of intrinsic malignant potential - exist? The question arises from the fact that, in spite of increased diagnoses of completely excised malignant melanoma (MM) in the last two decades, mortality from advanced metastatic disease has not decreased. After a brief review of the literature, the author proposes that the existence of CIHIMELL could be affirmed through post mortem dermoscopy and histological study of any pigmented lesion, clinically or dermoscopically suspected, of several deceased patients undergoing necropsy for death causes unrelated to MM. Should the cumulative prevalence of merely histological melanomas turn out to be exceedingly high and not commensurable with the current death rates of true MM, the discrepancy would tangibly prove that indolent pigmented lesions with morphological aspect of melanoma do exist. This would clearly introduce difficulties that could satisfactorily be dealt with only through a paradigm shift in melanoma surveillance and diagnosis (which could also allow to add a piece of "encouraging uncertainty" to the patient-physician relationship). However, it can be expected that such an enterprise would be countered by several vested academic and commercial interests.
\end{abstract}

Keywords: Melanoma, dermoscopy, screening, overdiagnosis, incidental tumors.

\section{INTRODUCTION}

For the last twenty years, an epidemic of malignant melanoma (MM) has been purported to be ongoing [14]. However, in spite of the introduction of dermoscopic techniques which are boasted to precociously diagnose this neoplasm, and the consequent increase in removal of "early" lesions later on histologically diagnosed as MM, deaths from advanced stages of the disease have not decreased $[1,2]$. It is sadly realistic to recognise that the current gold standard for the diagnosis of MM is still death of the patient from metastases [1,4], i.e., the actual unfavourable biologic behaviour in that given, concrete case - not surrogate morphological patterns. Does this discrepancy allow to hypothesize that a majority of lesions with the histological aspect of $\mathrm{MM}$ are not doomed to progress to overt disease [1$3,5,6]$ ? Can a scenario very similar to that of prostate cancer, where the distinction between "tiger" and "pussy cat" tumors [7] has become a classical matter of debate, be proposed for MM as well [8]?

\section{ARE ALL "MALIGNANT MELANOMAS" REALLY MALIGNANT?}

The problem of overdiagnosis of cancer has emerged as a challenging one in the field of modern oncology. As limpidly stated by Welch \& Black [6], "an overdiagnosed patient has a tumor that fulfils the pathological criteria for [a] cancer", which however "never progresses [...], regresses [...] or progresses

${ }^{*}$ Address correspondence to this author at the Dermatology \& STD, 7 Via Sant'Alessandro Sauli, 20127 Milan, Italy; Tel: +39-(0)2-2822542;

E-mail: progderm@katamail.com slowly enough that the patient dies of other causes before the cancer becomes symptomatic" (author's emphases). Yet, it is an awkward topic, because it clashes with the consolidated conviction that "early diagnosis at any cost" is the best enterprise in the field. As to MM, Lipsker and co-workers have clearly pointed out [3] that the umbrella term "melanoma" could cover three different entities, morphologically related, but not equivalent as to their epidemiologic and, more important, biologic behaviour. These are:

\section{Type 1 Melanomas}

Thick tumours, with stable incidence, rapid growth, unpredictable onset, and poor prognosis: this type seems to coincide with the phenotype of "rapidly growing melanomas" [9], or of "thick nodular melanoma" [10] or, from the viewpoint of a busy, coarse practical clinician, "the very melanoma, which has grown so big within few weeks: let's cut it off at once". Such a clinician is not sceptical about depositions of patients testifying that their skin blot has grown rapidly for some weeks and/or was not present before [11]. Of interest, such MMs do not seem to be related to sun exposition, being underrepresented on the trunk and overrepresented on the head and neck skin [3]. This could mean that at least some of such patients are prone to be underscreened, because they could feel not to be exposed to "common risk factors" for MM;

\section{Type 2 Melanomas}

Slow-growing lesions of the trunk and of the limbs, related to intermittent sun exposure: their incidence is 
increasing, and their slow growth can be tracked through application of the well known $A B C D E$ rule [3];

\section{Type 3 Melanomas}

Similar to Type 2 as to slow growth and increasing incidence, but related to continuous sun exposition: accordingly, they mainly interest head and neck regions. $A B C D E$ rule applies to their discovery as well [3].

It goes without saying that Type 1 melanomas are genuinely malignant. Now, the question is: if left untreated, all of the Types 2 and 3 lesions are doomed to merge into a Type 1-like natural history? If not, how many would do so?

In the last decade, the concept, or the working hypothesis at least, that "clinically insignificant, histological melanoma-like lesions" could exist, has sneakingly emerged under denominations such as "biologically benign melanomas" [12] or "overdiagnosed melanomas", as opposed to "clinically significant" ones [6]. The author would propose the abbreviation CIHIMELL (to be pronounced 'sı-hı-me'l, in vague assonance with "melanoma facsimile") for "Clinically Insignificant, HIstological MElanoma-Like Lesions": this does not sound more cumbersome than other odd pseudodiagnostic [4] acronyms used in this nosographic border field, such as MelTUMP (melanocytic tumours of unknown malignant potential) [13] or SAMPUS (superficial atypical melanocytic proliferation of unknown significance) [4]. Note that the term "incidental melanoma", deliberately used in the title of the present paper with a challenging aim, and introduced more than thirty years ago by Monk and coworkers [14], originally referred to truly (or bona fide so believed) malignant lesions discovered by chance during unrelated medical examination. This specification is mandatory in order to avoid further confusion in a field that seems already messy by itself, because accurate reading of that report [14] induces to suspect that even some of the cases there reported could be brought again to the nosographic intricacies highlighted in the present paper.

Now and anyway, the problem can be enunciated as follows: do CIHIMELL exist? If so, how many MeITUMP, SAMPUS and even Lipsker's type 2 and 3 melanomas merge into this prognostic category?

\section{AN UNPRACTICAL PROPOSAL}

How can the burden of putative CIHIMELL be quantified? The first step should be to provide a reliable overall esteem, in the rigorous form of a quantitative rate. The author would propose a post mortem histologic study of any clinically or dermoscopically suspect pigmented lesion of several deceased patients undergoing necropsy for death causes unrelated to MM. Obviously, such a transversal study could not be performed during lifespan, because of the large, unacceptable number of surgical procedures required (albeit this was partially performed even in vivo in one selected case of dysplastic naevus syndrome [15] possibly the ideal target subpopulation!). The study could definitely provide a reliable direct (i.e., not based on mathematical inference from epidemiological models or on bare intuitive impression) esteem of the overall prevalence of "histologic melanomas". Clearly, two still indistinguishable types of lesions would merge into the cauldron represented by the rate numerator, to wit:

1. True "incidental melanomas", in the sense of Monk [14] (that is, doomed to progress and cause metastatic disease), no matter whether thin or thick ones;

2. Indolent, morphologically melanoma-like, pigmented lesions (i.e., genuine CIHIMELL), which could have been incidentally discovered.

Should such a cumulative prevalence turn out to be exceedingly high and not commensurable with the current rates of true MM (which would turn out as a defined subset of the "melanoma universe"), the discrepancy would tangibly prove that indolent pigmented lesions with morphological aspect of melanoma do exist, and this should prompt to search for more reliable markers of benignity/malignity (likely molecular or genomic ones), possibly in a biologic archive provided by the study, to be retrospectively compared with samples coming from patients with overtly full-blown, true MM.

The author started proposing such a study in 2007, but objections have been apparently overwhelming. An anonymous British epidemiologist stated that such a study would be quite impractical: for a raw incidence of 10.000 MM per year in the United Kingdom (population implicitly approximated to 50 millions), this would mean an incidence of $1 / 5.000$. If there were $10 \mathrm{CIHIMELL} \mathrm{for}$ every truly malignant melanoma, the moles of at least 500 corpses should be examined to find out one, and, in order to get a statistically significant sample, thousands of corpses should undergo pathological examination. Such objections show that the author's 
proposal has been misunderstood, in that the aim is not to differentiate "pussy cats" from "tigers"; rather, it is to quantify the overall number of incidental "histological melanomas" in corpses. The point is: take into account the prevalence of histological melanomas related to the number of suspect nevi, not of patients - here is the apt denominator. Consider one hundred typical patients with dysplastic nevus syndrome, each bearing 100 lesions: if we analysed all 10.000 pigmented lesions, and found 20 histological melanomas (no matter how distributed in the sample), this would already represent tangible evidence that an excess of clinically insignificant MM-like lesions exist. Such an approach would not force pathologists to work overtime, if we consider, for instance, that in Australia $56 \%$ of consultations in skin cancer clinics are sent for biopsy, and that the yield is one melanoma for 29 benign lesions excised $[4,16]$. Moreover, biostatisticians would surely be able to find a shortcut, e.g., through a sequential design.

\section{A PROBLEMATIC CONCLUSION}

Imagine that the existence of CIHIMELL were definitely recognised. This surely would not be the end of the dispute. Rather, it would introduce overcoming difficulties of the "I-Don't-Know" type [17], which neither practical clinicians nor pathologists faced with real cases could be ready to cope with. Probably, if we astray from the clinical progression of the lesion, the problem posed by the recognition of true early lethal MM is beyond the reach of either clinical dermatologic, dermoscopic, or dermatopathological criteria, and we should shift away from the obsolete dull paradigma of defining and revising stricter and subtler clinicopathological criteria that lead nowhere further . Unfortunately, attempts to discover the "right change in tissue" making the differential diagnosis are in an embryonic stage. For instance, metabolomic fingerprints of $\mathrm{MM}$ can be retrieved from biopsy samples [18], but we probably need something alike that can be derived from intact, in vivo lesions: otherwise, we shall slip back into the biopsy epidemic. Notwithstanding, urologists do recognise that pussy cats exist [7] and have learnt to act consequently - why should we, dermatologists, refrain from this? Do we fear that the uncertainty introduced by such a highly probable, irrefutable result, could condition our diagnostic serenity for many years? But what would the practical consequences of such an explicit acknowledgement be? Could clinical dermatologists be eventually told - and tell their patients - that a great deal of morphological objects which looked like melanomas under certain viewpoints (dermoscopy, histological pattern, even confocal microscopy) were indeed not such a thing? We must remember that clinicians are relentlessly urged by either lay people or experts in the field to screen any stable focal skin lesion, no matter whether pigmented or not, because it could turn out to be a "melanoma incognito" [19], a concept that the author has vehemently challenged [20], because it merely refers to histologically melanoma-like objects excised after routine dermoscopic examination of "nonsuggestive" [19] skin lesions, to wit, non-pigmented, non-evolving, nonatypical, or even trivial ones, such as insect bites [19]!

The author is aware of further limitations inherent in his proposal. The study would be expensive, and would take a long time. Several technical difficulties would ensue (multiple different areas from single combined pigmented lesions to be evaluated, sampling problems, cost of ancillary procedures, bioethical and legal issues related to corpse dissection). It should be underscored, however, that some patients could be paradoxically solaced by the possibility that their excised "melanomas" could be not such a sinister thing: sometimes, uncertainty adds hope to the patientphysician communication, and this can be encouraging. Unfortunately, extended clienteles for videodermoscopic \& spot-mapping "screenings" have been built up, and several vested academic, industrial, medical and legal interests would militate against such a "wasteful enterprise". However, the author believes that such a first step is to be taken. Otherwise, things will be left as they are, involved medical people will persist to err "on the safe side", and savage excision of any focal, "suspect, properly evaluated" pigmented lesion will further fuel the "melanoma epidemic".

\section{REFERENCES}

[1] Swerlick RA, Chen S. The melanoma epidemic. Is increased surveillance the solution or the problem? Arch Dermato 1996; 132: 881-4. https://doi.org/10.1001/archderm.132.8.881

[2] Dennis LK. Analysis of the melanoma epidemic, both apparent and real. Data from the 1973 through 1994 surveillance, epidemiology, and end results program registry. Arch Dermatol 1999; 135: 275-80. https://doi.org/10.1001/archderm.135.3.275

[3] Lipsker D, Engel F, Cribier B, Velten M, Hedelin G. Trends in melanoma epidemiology suggest three different types of melanoma. Br J Dermatol 2007; 157: 338-43. https://doi.org/10.1111/j.1365-2133.2007.08029.x

[4] Weyers $W$. The "epidemic" of melanoma between under- and overdiagnosis. J Cutan Pathol 2012; 39: 9-16. https://doi.org/10.1111/j.1600-0560.2011.01831.x

[5] Levell NJ, Beattie CC, Shuster S, Greenberg DC. Melanoma epidemic: a midsummer night's dream? $\mathrm{Br} \mathrm{J}$ Dermatol 2009; 161: 630-4.

https://doi.org/10.1111/j.1365-2133.2009.09299.x 
[6] Welch HG, Black WC. Overdiagnosis in cancer. J Natl Cancer Inst 2010; 102: 605-13. https://doi.org/10.1093/jnci/dja099

[7] Boccon-Gibod L. Editorial: significant versus insignificant prostate cancer - can we identify the tigers from the pussy cats? J Urol 1996; 156: 1069-70. https://doi.org/10.1016/S0022-5347(01)65704-5

[8] Glusac EJ. The melanoma "epidemic": lessons from prostate cancer. J Cutan Pathol 2011; 39: 17-20. https://doi.org/10.1111/j.1600-0560.2011.01848.x

[9] Liu W, Dowling JP, Murray WK, McArthur GA, Thompson JF, Wolfe R, Kelly JW. Rate of growth in melanomas. Characteristics and associations of rapidly growing melanomas. Arch Dermatol 2006; 142: 1551-8. https://doi.org/10.1001/archderm.142.12.1551

[10] Demierre MF, Chung C, Miller DR, Geller AC. Early detection of thick melanomas in the United States. Beware of the nodular subtype. Arch Dermatol 2005; 141: 745-50. https://doi.org/10.1001/archderm.141.6.745

[11] Lipsker D. Growth rate, early detection, and prevention of melanoma. Melanoma epidemiology revisited and future challenges. Arch Dermatol 2006; 142: 1638-40. https://doi.org/10.1001/archderm.142.12.1638

[12] Argenziano G, Zalaudek I. Do we detect a new spectrum of biologically benign melanomas in the dermoscopy era? Expert Rev Dermatol 2006; 1: 361-7. https://doi.org/10.1586/17469872.1.3.361

[13] Cerroni L, Barnhill R, Elder D, Gottlieb G, Heenan P, et al. Melanocytic tumors of uncertain malignant potential. Results of a tutorial held at the XXIX symposium of the International
Society of Dermatopathology in Graz, October 2008. Am J Surg Pathol 2010; 34: 314-26. https://doi.org/10.1097/PAS.0b013e3181cf7fa0

[14] Monk BE, Clement MI, Pembroke AC, DuVivier A. The incidental malignant melanoma. BMJ 1983; 287: 485-6. https://doi.org/10.1136/bmj.287.6390.485

[15] Brod C, Schippert W, Breuninger H. Ausgeprägtes dysplastisches Nävussyndrom mit Entwicklung multipler Melanome. Operatives Konzept zur Prophylaxe. J Dtsch Dermatol Ges 2009; 7: 773-5. https://doi.org/10.1111/j.1610-0387.2009.07095 supp.x

[16] McCalmont TH. In my opinion. J Cutan Pathol 2011; 38: 268. https://doi.org/10.1111/j.1600-0560.2010.01661.x

[17] Foucar E. Debating melanocytic tumors of the skin: does an «uncertain diagnosis» signify borderline diagnostic skill? Am J Dermatopathol 1995; 17: 626-34. https://doi.org/10.1097/00000372-199512000-00020

[18] Abaffy T, Duncan R, Riemer DD, Tietje O, Elgart G, et al. Differential volatile signatures from the skin, naevi and melanoma: a novel approach to detect a pathological process. PloS One 2010; 5: e13813. https://doi.org/10.1371/journal.pone.0013813

[19] Argenziano G, Zalaudek I, Ferrara G, Johr R, Langford D, et al. Dermoscopy features of melanoma incognito: indications for biopsy. J Am Acad Derrmatol 2007; 56: 508-13. https://doi.org/10.1016/j.jaad.2006.10.029

[20] Capella GL. Systematic video dermatoscopy search for melanoma incognito: a call for quantitative specifications. J Am Acad Dermatol 2008; 59: 533. https://doi.org/10.1016/j.jaad.2008.04.035

DOI: http://dx.doi.org/10.30683/1929-2279.2019.08.08

(C) 2019 Giovanni Luigi Capella; Licensee Neoplasia Research.

This is an open access article licensed under the terms of the Creative Commons Attribution Non-Commercial License (http://creativecommons.org/licenses/by-nc/3.0/) which permits unrestricted, non-commercial use, distribution and reproduction in any medium, provided the work is properly cited. 